\title{
Co-production of evidence for policies in Thailand: from concept to action
}

\author{
Viroj Tangcharoensathien and colleagues apply the "triangle that moves the mountain" to \\ analyse the co-production of evidence for health policy making in Thailand
}

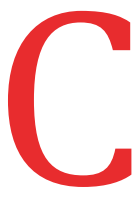

o-produced knowledge is increasingly being used to inform health policy decisions. $^{1-3}$ In Thailand, legal provisions set out in the 2017 constitution mandate the state to convene public hearings with affected communities before approving projects which may have health and wellbeing implications. ${ }^{4}$ Public involvement in decisions about health systems is not new in Thailand and has been a part of its health system's reforms since the 1990s. ${ }^{5}$

The co-production concept known as the "triangle that moves the mountain," was described in 1997 by Prawase Wasi, a highly recognised health leader in Thailand. The triangle has three power poles representing policy makers, politicians, local administrative organisations, and government services (government sector); civil society, communities, and citizens (people's sector); and academia, think tanks, and research institutions, (knowledge sector). The core principle is that the three groups work together to achieve a common goalthat is, "to move the mountain." The triangle concept promises greater policy

\section{KEY MESSAGES}

- Thailand uses co-production of evidence, based on the concept of the "triangle that moves the mountain," to support health policy making

- The annual national health assembly is a key platform for interactions between multiple stakeholders to adopt resolutions through consensus

- Strengthened research capacity and citizens' needs and social movements have contributed to the development of relevant public health policy for Thailand's citizens

- Government and political stakeholders are responsive to citizens in the coproduction process, notably through legislation on priority health challenges acceptance and sustainability than a traditional top-down policy approach. ${ }^{6}$

The triangle concept has been practised in a range of health policy arenas in Thailand, including the landmark health reform for the introduction of universal health coverage (UHC) in 2002. A citizenled draft UHC bill, endorsed by 50000 electors, was proposed to the legislative bodies for consideration at the legislative process of the National Health Security Act and was finally adopted in 2002 . $^{7}$ This is mandated by article 133 in the 2017 constitution, which promotes citizen participation in an "initiative process," a form of direct democracy whereby citizens can propose legislation. ${ }^{8}$ This triangle concept also underpins the Thai National Health Assembly (NHA), which is mandated by a legal provision in the 2007 National Health Act. Established in 2008, the NHA provides a structured process for a range of stakeholders, including citizens, civil society, academic and research organisations, multisectoral government agencies, and the private sector, to develop and negotiate public health policy resolutions through consensus. ${ }^{9}$ Although there are challenges to the process, including the need to develop stronger links to decision making, it still provides a strong model for participatory public policy making. ${ }^{10}$ The model has been supported by the strengthening and institutionalisation of country capacity to generate evidence and the retention of well trained health researchers in Thailand. ${ }^{11}$

To further understand the co-production of knowledge for health policy making in Thailand, we reflect on the similarities and synergies between the triangle concept, which emerged in Thailand as a way to deal with complex, often unmovable problems, and key principles of knowledge co-production. Norström and colleagues emphasise that co-production should be context based, pluralistic, goal oriented, and interactive. ${ }^{2}$ Although Norström and colleagues' principles focus on research sustainability, they bring to light the different processes and interactions between the three power poles that are needed for co-production to meaningfully inform health policy making and reform.

\section{Co-production in action}

The first principle is that co-production processes should be context based. The co-production of knowledge should be situated within the social, economic, and ecological context and consider the different needs and interests of stakeholders. For example, the agendas of NHA meetings were set in response to persistent health systems and policy challenges which required multistakeholder input and actions.

The covid-19 pandemic reinforces context as a key entry point for co-production in Thailand. Preparations for the potential upsurge in demand for critical resources such as intensive care beds, ventilators, and haemodialysis machines, triggered the development of a national guideline on the prioritisation and allocation of critical resources during the pandemic. The first author (VT) convened a series of multistakeholder consultations to seek different perspectives on resource allocation, such as medicolegal, ethical, and equity considerations as well as public acceptability. Stakeholders included lawyers, medical experts, ethicists, civil society representatives, and religious scholars. ${ }^{12-14}$ Researchers assisted in compiling international evidence and crafting the first draft of the guideline, but the diverse stakeholder groups helped to contextualise the challenges with resource allocation. They contributed to shaping the content so that the guideline fitted with local laws, medical standards, and practices, as well as sociocultural beliefs and values. The draft guideline was presented to policy makers to decide whether it was necessary to implement the guideline. To date, the guideline has yet to be applied because the demand for critical resources during covid-19 has not outstripped supply.

This example also shows the principle of pluralism and the ways in which the three stakeholders in the 
triangle brought different expertise and experiences to evidence generation and policy development. This principle also underlies the importance of recognising and addressing unequal power relations among stakeholders in the co-production process. ${ }^{15}$ For example, in 2011, the Cabinet (Council of Ministers) endorsed a 2010 NHA resolution on the total ban of chrysotile asbestos, which mandated the Ministry of Industry to implement an immediate ban. The uneven interest and buy-in from stakeholders, particularly the industries which opposed the ban, caused long implementation delays. In particular, misinformation on the safe use of chrysotile and pressure from major chrysotile exporting countries were problems. ${ }^{16}$ Despite the support from consumer protection groups, which helped to synthesise the evidence and raised awareness of the problem as well as participating in the NHA, implementation was hampered by possible "regulatory capture.” This is when regulatory authorities, instead of safeguarding public interest, act in favour of the industries or interested groups they are supposed to regulate. ${ }^{17}$ Although the Cabinet endorsed the resolution, the total ban was not fully implemented as the NHA process was not designed to enforce implementation. This is a challenge when power and authority lie with state actors. Nevertheless, monitoring and public reporting of progress can be an effective way to hold government and implementers to account. ${ }^{16}$ The 2019 NHA resolution reviewed the lack of progress of implementing the 2011 resolution and reaffirmed a total ban by 2022 .

Not only is the triangle concept "to move the mountain" based on an understanding of context and the participation of diverse stakeholders, this concept also requires that multiple stakeholders agree and work towards achieving the principle of shared goals. For example, in 2002, the universal coverage scheme (UCS), which provides insurance for the population not covered by private sector or government employee schemes, did not cover renal replacement therapy (RRT) for patients with end stage kidney disease, when the other two schemes did. The reason given for this was the high cost of treatment over a person's lifetime and that the health system in 2002 was not ready to provide universal RRT. ${ }^{18}$

In response to this lack of access, a range of stakeholders came together to produce evidence to address the inequitable access to lifesaving RRT under the UCS. These stakeholders included the Friends of
Kidney Disease Association, established by patient groups in 2006, and other civil society organisations; the Nephrology Society, representing health professionals; the National Health Security Office, as the UCS manager; and the International Health Policy Program (IHPP), representing the research sector. All groups shared a common goal of equitable access to RRT. Studies were undertaken to rebut the rationale for not including RRT in the UCS benefit package and focused on quality of life of patients having haemodialysis and peritoneal dialysis, ${ }^{19}$ the financial effect on poor households, ${ }^{20}$ cost comparison of haemodialysis, peritoneal dialysis, and kidney transplantation, the cost effectiveness of RRT, ${ }^{21}$ and the budget implications of covering RRT. ${ }^{22}$ Patient group members, who were most affected by the lack of access to the life saving treatment or impoverished from outof-pocket payment, also brought their experience to the research and policy discussions.

In response to the apparent inequity across the three insurance schemes, the legitimacy of broad stakeholder support, robust evidence, as well as the obvious needs of those missing out on life saving RRT, the Cabinet approved the National Health Security Office's proposal to include RRT (peritoneal dialysis, haemodialysis, and kidney transplantation) into the UCS benefit package with full subsidies in $2007 . .^{23}$ The "peritoneal dialysis first" policy was also adopted in 2007, providing improved access to those living far from haemodialysis centres. When peritoneal dialysis was not successful, haemodialysis was also fully funded. ${ }^{24}$ Notably, the co-production process and a reality check from stakeholders provided a major turning point for universal RRT and the peritoneal dialysis first policy. Universal RRT has saved the lives of nearly 50000 UCS members. ${ }^{25}$

The fourth principle reiterates the importance of the interactions and active engagement among stakeholders from the different power poles throughout the co-production process, starting from framing the problem and setting the agenda to generating evidence and the dissemination of findings. These interactions also increase the likelihood that the generated knowledge will be incorporated into policy decisions and implemented in practice. For example, in 2010, stakeholders from the different power poles, including representatives from multiple government agencies, such as health, social welfare, and education, and civil society organisations (including gender and reproductive health rights groups), agreed on an NHA resolution to reduce adolescent pregnancy. This initiative led to legislating the Prevention and Solution of the Adolescent Pregnancy Problem Act in 2016. Although it took several years between the adoption of NHA resolution in 2010 and the legislation in 2016, during this period, stakeholders from the different government agencies, academia, civil society, gender groups as well as young people themselves, worked together to generate evidence to inform the content of the draft bill. In 2016 the prime minister's committee on the prevention of adolescent pregnancy was established to oversee the implementation of the act. It also had diverse membership, including male and female representatives from the Children and Youth Council of Thailand. Provincial children and youth councils also had an active role in implementing the act. $^{26}$

\section{Conclusion}

Strong research capacity, one of the three power poles, has allowed Thailand to embrace "the triangle that moves the mountain" concept in health systems' decision making in response to complex challenges. Citizens' needs and social movements, a second power pole, have facilitated policy acceptance or even policy ownership, as shown in the case of the universal renal replacement therapy policy. These two power poles contribute to the successful co-production of decision making, while government and political stakeholders are responsive to citizens through their engagement in the co-production process, such as in the case of preventing adolescent pregnancy and the endorsement of the total ban on chrysotile asbestos.

The NHA is a key enabling factor for co-production and citizens' engagement in health policy decision making in Thailand. Ensuring a diversity of stakeholders in agenda setting and evidence generation as well as in support of policy decisions and implementation is critical to the co-production process. The relationships among stakeholders are boosted by a shared goal, whether it be in the context of a public health emergency such as covid19 , life threatening end-stage renal disease, or the prevention of adolescent pregnancy. The three power poles, underpinned by the four principles of co-production, all contribute to the development of relevant public health policy for citizens in Thailand. 
We acknowledge the contributions by all partners in and outside Ministry of Public Health for evidence informed policy in responses to COVID-19. We acknowledge the institutional grant from the Thailand Science Research and Innovation (TSRI) under the senior research scholar on health policy and system research to IHPP.

Contributors and sources:VT and WP conceived and developed the manuscript. SS (the guarantor of the paper) and PS provided conceptual and technical support in the manuscript. AL, WI, WW, and OC provided technical information in the case studies. All the authors contributed to the drafting of the manuscript and approved the final manuscript before submission.

Competing interests: We have read and understood BMJ policy on declaration of interests and have no relevant interests to declare.

Provenance and peer review: Commissioned; externally peer reviewed.

This article is part of a series produced in conjunction with the WHO and the Alliance for Health Policy Systems and Research with funding from the Doris Duke Charitable Foundation. The BM/ peer reviewed, edited, and made the decision to publish.

Viroj Tangcharoensathien, researcher ${ }^{1}$

Supakit Sirilak, director general ${ }^{2}$

Piyamitr Sritara, professor ${ }^{3}$

Walaiporn Patcharanarumol, researcher ${ }^{1,4}$

Angkana Lekagul, researcher ${ }^{1}$

Wanrudee Isaranuwatchai, researcher ${ }^{5,6}$

Woranan Wittayapipopsakul, researcher ${ }^{1}$

Orana Chandrasiri, researcher ${ }^{1}$

${ }^{1}$ International Health Policy Programme, Ministry of Public Health, Nonthaburi, Thailand

${ }^{2}$ Office of Permanent Secretary, Ministry of Public Health, Bangkok, Thailand

${ }^{3}$ Faculty of Medicine, Ramathibodi Hospital, Mahidol University, Bangkok, Thailand

${ }^{4}$ Global Health Division, Ministry of Public Health, Nonthaburi, Thailand

${ }^{5}$ Health Interventions and Technology Assessment Programme, Ministry of Public Health, Nonthaburi, Thailand

${ }^{6}$ Institute of Health Policy, Management and Evaluation, University of Toronto, Toronto, Canada

Correspondence to: VTangcharoensathien

Tangcharoensathienviroj@ihpp.thaigov.net

\section{(®) $(1) \Theta$ OPEN ACCESS}

This is an Open Access article distributed under the terms of the Creative Commons Attribution IGO License (https://creativecommons.org/licenses/ by-nc/3.0/igo/), which permits use, distribution, and reproduction for non-commercial purposes in any medium, provided the original work is properly cited.

\section{D) Check for updates}

1 Elwyn G, Nelson E, Hager A, Price A Coproduction: when users define quality. BMJ Qual Saf 2020;29:711-6. doi:10.1136/ bmjqs-2019-009830

2 Norström AV, Cvitanovic C, Löf MF, et al. Principles for knowledge co-production in sustainability research. Nat Sustain 2020;3:182-90. doi:10.1038/s41893019-0448-2

3 Rycroft-Malone J, Burton CR, Bucknall T, Graham ID, Hutchinson AM, Stacey D. Collaboration and co-production of knowledge in healthcare: opportunities and challenges. Int J Health Policy Manag 2016;5:221-3. doi:10.15171/ ijhpm.2016.08

4 Government Gazette. Constitution of the Kingdom of Thailand B.E.2560 2017. https://cdc parliament.go.th/draftconstitution2/ewt_dl_link. php?nid=1460\&filename=index]

5 Towse A, Mills A, Tangcharoensathien V. Learning from Thailand's health reforms. BMJ 2004;328:1035. doi:10.1136/bmj.328.7431.103

6 Wasi P. Triangle that moves the mountain and health systems reform movement in Thailand. Hum Resour Heal Dev / 2000;4:106-10

7 Pitayarangsarit S. The introduction of the universal coverage of health care in Thailand: Policy responses. [PhD thesis]. London School of Hygiene \& Tropical Medicine, 2005. doi:

8 Office of the Council of State. Constitution of the Kingdom of Thailand. 2007. http://web.krisdika. go.th/data/outsitedata/outsite21/file/Constitution_ of_the_Kingdom_of_Thailand.pdf

9 Chuengsatiansup K. Deliberative action: civil society and health systems reform in Thailand. National Health Commission Office, 2008. https://www. sem100library.in.th/medias/4371.pdf

10 World Health Organization. Rajan D, Mathurapote $\mathrm{N}$, Putthasri W, et al. The triangle that moves the mountain: nine years of Thailand's National Health Assembly (2008-2016). World Health Organization, 2017. https://apps.who.int/iris/ handle/10665/260464

11 Pitayarangsarit S, Tangcharoensathien V. Sustaining capacity in health policy and systems research in Thailand. Bull World Health Organ 2009;87:72-4. doi:10.2471/BLT.07.044479

12 Meyfroidt G, Vlieghe E, Biston P, et al. Ethical principles concerning proportionality of critical care during the 2020 COVID-19 pandemic in Belgium: advice by the Belgian Society of Intensive care medicine. 2020. https://www.zorgneticuro.be/sites/ default/files/general/COVID-19-ethical_final_c. cleaned.pdf

13 New York State Department of Health. Ventilator allocation guidelines. 2015. https://www.health. ny.gov/regulations/task_force/reports_publications/ docs/ventilator guidelines.pdf

14 Notfallmedizin DIVfl-u. Entscheidungen über die Zuteilung von Ressourcen in der Notfallund der Intensivmedizin im Kontext der COVID-19-Pandemie 2020. https://www.divi.de/empfehlungen/ publikationen/covid-19/1540-covid-19-ethikempfehlung-v2/file
15 Fung A. Varieties of participation in complex governance. Public Adm Rev 2006;66(suppl 1):6675. doi:10.1111/j.1540-6210.2006.00667.x

16 Kanchanachitra C, Tangcharoensathien V, Patcharanarumol W, Posayanonda T. Multisectoral governance for health: challenges in implementing a total ban on chrysotile asbestos in Thailand. BMJ Glob Health 2018;3(Suppl 4):e000383. doi:10.1136/bmjgh-2017-000383

17 Gyawali B, Goldstein DA. The US Food and Drug Administration's approval of adjuvant sunitinib for renal cell cancer: a case of regulatory capture?JAMA Oncol 2018;4:623-4. doi:10.1001/ jamaoncol.2017.5697

18 Tantivess S, Werayingyong P, Chuengsaman P, Teerawattananon Y. Universal coverage of renal dialysis in Thailand: promise, progress, and prospects. BMJ 2013;346:f462. doi:10.1136/bmj.f462

19 Petkham M, Petkham LIntolo S. Comparative study of quality of life between end stages renal disease patients treated with continuous ambulatory peritoneal dialysis and hemodialysis at Sawangdaendin Crown Prince Hospital. J Nurs Heal Care. 2020;38:138-46.

20 Prakongsai P, Palmer N, Uay-Trakul P, Tangcharoensathien V, Mills A. The implications of benefit package design: the impact on poor Thai households of excluding renal replacement therapy. Int Dev 2009;21:291-308. doi:10.1002/jid.1553

21 Teerawattananon Y, Mugford M, Tangcharoensathien V. Economic evaluation of palliative management versus peritoneal dialysis and hemodialysis for end-stage renal disease: evidence for coverage decisions in Thailand. Value Health 2007;10:61-72. doi:10.1111/j.1524-4733.2006.00145.x

22 Nephrology Society of Thailand. Report of Thailand renal replacement therapy year 2008. 2008. https:// www.nephrothai.org/wp-content/uploads/2020/08/ THAILAND_RENAL_REPLACEMENT_THERAPY YEAR_2008.pdf

23 National Health Security Office. History of the renal failure fund [in Thai]. https://www.nhso.go.th/ ARCHIVES/section4/detail5.aspx

24 Kasemsup V, Prakongsai P, Tangcharoensathien $\checkmark$. Budget impact analysis of including renal replacement therapy in the benefit package of universal coverage in Thailand. Value Health 2006;9:A385. doi:10.1016/S10983015(10)63770-9

25 Chuengsaman P, Kasemsup V. PD first policy: Thailand's response to the challenge of meeting the needs of patients with end-stage renal disease. Seminars in nephrology. Semin Nephrol 2017;37:287-95. doi:10.1016/j. semnephrol.2017.02.008

26 Ministry of Public Health, United Nations Population Fund, Asian Forum of Parliamentarians on Population and Development, Thai Health Promotion Foundation. The Prevention and Solution of the Adolescent Pregnancy Problem Act, BE. 2559 (2016).https:// thailand.unfpa.org/sites/default/files/pub-pdf/ AP\%20Act\%20infographic_en_web.pdf

Cite this as: $B M J$ 2021;372:m4669

http://dx.doi.org/10.1136/bmj.m4669 